\title{
Correction to: It is time for an organised, scientific approach to the application of patient-reported outcome measures in clinical studies and trials
}

\author{
Stephen P. McKenna ${ }^{1,2}$ (D)
}

Published online: 26 June 2019

(C) International League of Associations for Rheumatology (ILAR) 2019

\section{References}

1. McKenna S (2019) It is time for an organised, scientific approach to the application of patient-reported outcome measures in clinical studies and trials. Clin Rheum 38:611-615

2. Gupta P, Parshad R, Balakrishna P, Saraya A, Makharia GK, Sachdeva S, Sharma R (2018) Angle of his accentuation is a viable alternative to dor fundoplication as an adjunct to laparoscopic Heller cardiomyotomy: results of a randomized clinical study. Dig Dis Sci 63:2395-2404

Publisher's note Springer Nature remains neutral with regard to jurisdictional claims in published maps and institutional affiliations.

The online version of the original article can be found at https://doi.org/ 10.1007/s10067-018-04403-2

Stephen P. McKenna

smckenna@galen-research.com

Galen Research, Manchester, UK

2 School of Health Sciences, University of Manchester, Manchester, UK 